\title{
EFEITO DA TESTOSTERONA NO DESENVOLVIMENTO DE Chrysomya albiceps (Wiedemann) (Diptera: Calliphoridae)
}

\author{
EFFECT OF TESTOSTERONE ON THE DEVELOPMENT OF \\ Chrysomya albiceps (Wiedemann) (Diptera: Calliphoridae)
}

Ana C. Ferrari ${ }^{1}$, Andjara T. C. Soares $^{2}$, Marco A. Guimarães ${ }^{3}$, Patrícia J. Thyssen ${ }^{4}$

\begin{abstract}
${ }^{1}$ Aluna de Iniciação Científica. ${ }^{2}$ Pós-graduanda. ${ }^{3}$ Docente, Centro de Medicina Legal -CEMEL, Departamento de Patologia da Faculdade de Medicina de Ribeirão Preto - USP. ${ }^{4}$ Docente, Departamento de Parasitologia do Instituto de Biociências de Botucatu - UNESP. CorRespondência: Profa. Dra. Patrícia Jacqueline Thyssen. Departamento de Parasitologia, Instituto de Biociências de Botucatu - UNESP. Distrito de Rubião Junior, s/no. 18618-000 Botucatu - SP. Brasil.

Tel: +55-14-38116239; fax: +55-14-38116078. E-mail: thyssenpj@yahoo.com.br
\end{abstract}

Ferrari AC, Soares ATC, Guimarães MA, Thyssen PJ. Efeito da testosterona no desenvolvimento de Chrysomya albiceps (Wiedemann) (Diptera: Calliphoridae). Medicina (Ribeirão Preto) 2008; 41 (1): 30-4.

RESUMO: A Entomologia Médico-Legal ou Forense pode ser definida como a aplicação do estudo de insetos e outros artrópodes que, em associação com procedimentos criminalísticos, têm o propósito de descobrir informações úteis para uma investigação. Atualmente, os insetos são uma alternativa confiável para análises toxicológicas, especialmente na ausência de tecidos e fluidos normalmente utilizados para esse propósito, pois estes armazenam algumas substâncias ingeridas, o que pode alterar a sua taxa de desenvolvimento, sendo este fato relevante na determinação da causa e do tempo de morte. Experimentos prévios de nosso laboratório sobre efeitos da testosterona na decomposição corporal sugeriram que este hormônio poderia interferir no desenvolvimento da fauna cadavérica. Com o objetivo de se investigar a influência da testosterona no desenvolvimento larval de Chrysomya albiceps, uma espécie comum na fauna cadavérica, um estudo experimental foi realizado a partir de ovos de uma colônia da referida espécie mantida em laboratório. Os ovos foram divididos em quatro grupos de 30 e colocados em potes de vidro com $50 \mathrm{~g}$ de dieta artificial cada, tendo sido a dieta acrescida de testosterona em dois deles. Pesagens foram realizadas de 12 em 12 horas durante todo o intervalo de crescimento larval. As larvas analisadas não apresentaram diferença nos estadios de desenvolvimento, porém as larvas do grupo experimental estavam com cinco vezes o peso das larvas do grupo controle e com tamanho aumentado. Tal resultado evidencia uma influência significativa da testosterona no crescimento de larvas de $C$. albiceps.

Descritores: Diptera. Esteróides. Entomologia, Forense. Medicina Legal.

\section{1- INTRODUÇÃO}

O estudo do intervalo pós-morte (IPM) constitui um dos temas mais complicados da ciência médico-legal, devido às circunstâncias que podem fazer variar a marcha e a fisionomia particular dos fenômenos putrefativos ${ }^{1}$.
A presença de insetos associados a restos humanos pode fornecer valiosas informações em investigações criminais e, portanto, é cada vez mais estudada e utilizada para tentar determinar o IPM. Esta área de estudo é denominada Entomologia MédicoLegal ou Forense e pode ser definida como a aplicação do estudo de insetos e outros artrópodes que, em 
associação com procedimentos criminalísticos, tem o propósito de descobrir informações úteis para uma investigação ${ }^{2,3,4}$.

Estudos mostram que as larvas dos insetos necrófagos, ao se alimentarem de um tecido, incorporam drogas e outras toxinas em seu próprio metabolismo $^{1,5}$. A identificação de uma droga através da análise de insetos imaturos foi feita pela primeira vez por Beyer et al. ${ }^{6}$ e, atualmente, os insetos são uma alternativa confiável para análises toxicológicas, especialmente na ausência de tecidos e fluidos normalmente utilizados para esse propósito ${ }^{5,7}$.

Em virtude disso, os dípteros e suas larvas que são encontrados em cadáveres podem contribuir consideravelmente para a identificação de substâncias exógenas presentes no corpo $^{8}$, ciência conhecida como entomotoxicologia.

Algumas drogas afetam a velocidade de desenvolvimento de insetos necrófagos, podendo indicar, por exemplo, um caso de morte por overdose ${ }^{1,5}$. Assim, é importante que se investigue os efeitos causados por certas substâncias no desenvolvimento dos insetos, uma vez que uma análise incorreta pode gerar dados imprecisos sobre a sua idade e, em conseqüência, prejudicar a estimativa do IPM, que é baseada no ciclo de vida do inseto.

O tecido escolhido pela larva para sua alimentação também deve ser considerado, pois o efeito de drogas no crescimento de imaturos difere de acordo com o tecido utilizado como alimento9 ${ }^{9}$. Muitos estudos têm sido realizados com diferentes tipos de drogas tentando elucidar as relações entre estas e o ciclo de vida das diferentes espécies de dípteros de interesse forense.

Um modelo experimental com ratos foi desenvolvido no Centro de Medicina Legal (CEMEL) da Faculdade de Medicina de Ribeirão Preto da Universidade de São Paulo (FMRP/USP) para estudar a influência de esteróides sexuais na decomposição corporal de ratos castrados. Na exumação, foram observadas diferenças de tamanho entre as larvas presentes nos corpos sem tratamento hormonal e aquelas presentes nos corpos com tratamento hormonal, sendo estas visivelmente maiores, principalmente no grupo que recebeu testosterona.

Em virtude disso, este trabalho foi realizado para estudar o efeito da testosterona no desenvolvimento larval de Chrysomya albiceps (Wiedemann) (Diptera: Calliphoridae). A principal implicação forense para isso é a necessidade de avaliar a existência de alguma dro- ga exógena influenciando o metabolismo larval, com a finalidade de não gerar dados errôneos que possam produzir um IPM incorreto.

De acordo com a literatura científica, $C$. albiceps é um dos principais insetos necrófagos e, devido à sua reconhecida importância forense, foi a espécie escolhida para a realização do experimento. Em experimento realizado com carcaças de porcos no sul de Goiás a espécie apareceu como a mais abundante representando $89,4 \%$ da fauna cadavérica ${ }^{10}$. Já em coletas realizadas em cadáveres humanos no Rio Grande do Norte, C. albiceps se apresentou como a segunda espécie em número de indivíduos ${ }^{11}$. Na região de Campinas, estado de São Paulo, experimentos com carcaças de porcos expostas em áreas urbanas apresentaram $C$. albiceps como espécie significativa da fauna regional ${ }^{12}$. Além disso, um levantamento faunístico realizado no CEMEL demonstrou que, na região de Ribeirão Preto, também há predominância dessa espécie na decomposição corporal.

\section{2- MATERIAL E MÉTODOS}

Uma colônia de $C$. albiceps foi estabelecida e mantida em laboratório para que sua geração $\mathrm{F}_{2}$ fosse usada nesse experimento. Os ovos obtidos foram divididos em quatro grupos de 30 e colocados em potes de vidro com $50 \mathrm{~g}$ de dieta artificial composta por água, leite em pó, levedo de cerveja, caseína, nipagim, agar e coração de frango (Estrada, Grella, Thyssen e Linhares - comunicação pessoal). Dos quatro grupos formados, em dois houve acréscimo de $0.4 \mu \mathrm{g}$ de testosterona/g de dieta, ou seja, $40 \mu \mathrm{g}$ de propionato de testoterona (Androgenol ${ }^{\circledR}$, Hertape, Brasil) diluídos em $100 \mu \mathrm{L}$ de óleo para cada $100 \mathrm{~g}$ de dieta. Dos dois grupos controles obtidos, apenas um foi utilizado para medida de massa, ficando o outro sem nenhum tipo de manipulação, o mesmo ocorrendo para os dois grupos tratados com testosterona. O peso das larvas foi verificado em intervalos de 12 horas durante seis dias. A comparação dos resultados entre os grupos controle e tratado com testosterona foi feita através do teste $t$ de Student.

\section{3- RESULTADOS E DISCUSSÃO}

As larvas do grupo controle e do grupo testosterona não apresentaram diferença em relação ao tempo de desenvolvimento nos diferentes estádios larvais. 
Todavia, as larvas do grupo experimental apresentaram a média do peso corporal 5 vezes maior que a média de peso das larvas do grupo controle $(6.0 \mathrm{mg}$ e
$1.2 \mathrm{mg}$ por larva, respectivamente. Tabela I) e a diferença verificada em seu tamanho é bastante nítida, como pode ser observado na Figura 1.

Tabela I: Somatória dos pesos e tempo de desenvolvimento de larvas de $C$. albiceps criadas em dieta com e sem adição de testosterona. Apesar de haver larvas suficientes para pesagem no grupo tratado, estas foram pesadas na mesma quantidade possível para o grupo controle, que se apresentava em menor número, a título de facilitar a comparação. A temperatura média da sala de criação foi de $24,51 \pm 1,66^{\circ} \mathrm{C}$, a temperatura média da estufa foi de $24,27 \pm 1,81{ }^{\circ} \mathrm{C}$ e a umidade relativa média foi de $57,27 \pm 6,34 \%$.

\begin{tabular}{ccll} 
Idade (horas) & Número de larvas pesadas & Controle & Testosterona 0,4 $\mu \mathbf{g} / \mathbf{g}$ de dieta \\
\hline 12 & Não haviam larvas emergidas & & $0 *$ \\
24 & 10 & $0 *$ & $0 * *$ \\
36 & 10 & $0 * *$ & 0 \\
48 & 8 & 0 & 0 \\
60 & 8 & 0 & 0,03 \\
72 & 8 & 0,01 & $0,03 * * *$ \\
84 & 5 & $0,006^{* * *}$ & 0,05 \\
96 & 4 & 0 & 0,07 \\
108 & 3 & 0 & 0,04 \\
120 & 1 & 0 & \\
132 & Não foram encontradas & & \\
\hline
\end{tabular}

* larvas de primeiro instar; ** larvas de segundo instar; ***larvas de terceiro instar.
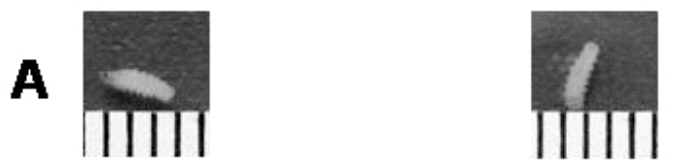

B
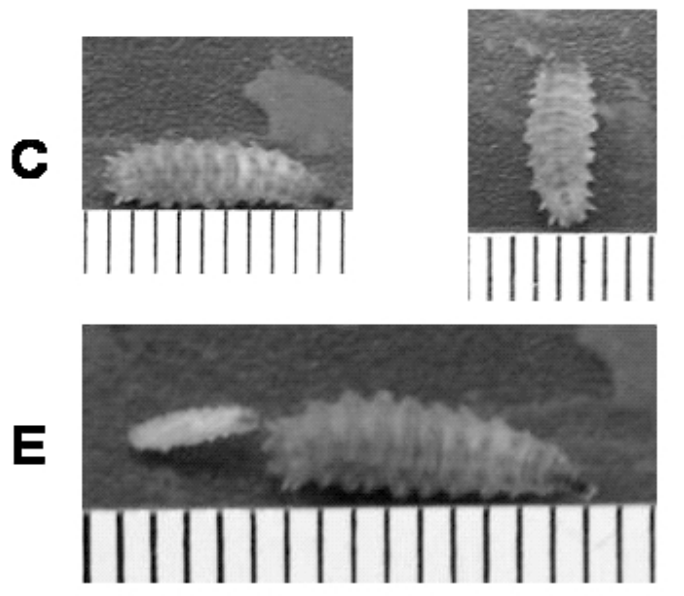

Figura 1: A) larva de C. albiceps pertencente ao grupo controle em posição horizontal. B) larva de $C$. albiceps pertencente ao grupo controle em posição vertical. C) larva de $C$. albiceps pertencente ao grupo tratado com testosterona em posição horizontal. D) larva de $C$. albiceps pertencente ao grupo tratado com testosterona em posição vertical. E) comparação das larvas de $C$. albiceps de ambos os grupos. A escala apresentada nas fotos está em milímetros. Todas as imagens foram obtidas na manhã do quinto dia de desenvolvimento (larvas no terceiro estádio), sem o auxílio de lupa, com câmera fotográfica digital Sony DSC-H2 6.0 Mpixels. 
Esse experimento mostrou diferença estatisticamente significativa de peso $(p \leq 0,01)$ obtida entre as larvas do grupo controle e as larvas do grupo tratado com testosterona.

Observou-se também um fato distinto durante o experimento. As larvas do grupo controle apresentaram mortalidade elevada em relação ao grupo tratado com testosterona, em que todas as larvas completaram seu desenvolvimento pós-embrionário. Não se obteve uma explicação para este fato, tendo em vista que todas as condições experimentais, exceto o tratamento com o esteróide, foram idênticas para os dois grupos. Contudo, não se pode descartar a hipótese de que a testosterona, ao promover um efeito anabólico no desenvolvimento das larvas possa evitar a mortalidade de larvas que poderia ser esperada mesmo em situações laboratoriais controladas.

\section{4- CONCLUSÃO}

Ainda é necessário realizar novos experimentos para investigar o motivo da maior sobrevivência das larvas do grupo tratado com testosterona. Todavia, pode-se sugerir que devida à diferença significativa obtida no desenvolvimento de larvas tratadas com este esteróide, a presença do hormônio masculino deva ser considerada como importante fato interveniente em análises entomológicas forenses para evitar erros durante a estimativa do IPM.

\section{5 - AGRADECIMENTOS}

À FAPESP pela bolsa de iniciação científica (processo $n^{\circ}$ 06/50257-4) e à CAPES pelo apoio financeiro.

Ferrari AC, Soares ATC, Guimarães MA, Thyssen PJ. Effect of Testosterone on the Development OF Chrysomya albiceps (Wiedemann) (Diptera: Calliphoridae). Medicina (Ribeirão Preto) 2008; 41 (1): 30-4.

ABSTRACT: Medico-Legal or Forensic Entomology can be defined as the application of the study of insects and other arthropods which, in association with criminalistic processes, have the the purpose of desovering useful information for an investigation. Nowadays, the insects are a reliable alternative for toxicological analysis, especially when tissues and liquids usually required for this purpose are absent, once insects store some ingested substances which can change their growth rate, being this a relevant fact in the determination of the cause and the time since death. Previous experiments in our laboratory on the testosterone effects on body decomposition suggested that this hormone could interfere in the cadaveric fauna development. With the objective of investigating testosterone influence on the Chrysomya albiceps larval development, a common species in cadaveric fauna, an experimental study was done from eggs of a laboratory maintained colony of this species. The eggs were divided in four groups of 30 and put in glass flasks with $50 \mathrm{~g}$ of artificial diet in each of them, with testosterone being added in two of them. The larvae were weighted each $12 \mathrm{~h}$ during all interval of the larval growing. The studied larvae did not present any difference in the stages of development, but larvae from the experimental group had 5 times the weight of the larvae from the control group and with bigger size. This result shows a significant influence of testosterone in the growth of $C$. albiceps.

Keywords: Diptera. Steroids. Forensic entomology. Forensic Medicine.

\section{REFERÊNCIAS}

1 - Oliveira-Costa J. Entomologia forense - os insetos a serviço da justiça. Cad Dir UCB 2002; 1(1): 41-51.

2 - Nuorteva P. Sarcosaprophagous insects as forensic indicators. In: Tedeschi CG, Eckert WG, Tedeschi LG, editors. Forensic medicine: a study in trauma and environmental hazards. New York: W.B; 1977. vol. II, p. 1072-95.
3 - Smith KGV. A manual of forensic entomology. Ithaca, NY: Cornell University Press; 1986.

4 - Hall RD. Introduction: perceptions and status of forensic entomology. In: Byrd JH, Castner JL, editors. Forensic entomology - The utility of arthropods in legal investigations. Boca Raton: CRC Press; 2001. p.1-16.

5 - Introna F, Campobasso CP, Goof ML. Entomotoxicology. Forensic Sci Int 2001; 120: 42-7. 
6 - Beyer JC, Enos WF, Stajic M. Drug identification through analysis of maggots. J Forensic Sci 1980; 25: 411-12.

7 - Bourel B, Tournel G, Hedouin V, Deveaux M, Goff ML, Gosset D. Morphine extraction in necrophagous insects remains for determining ante-mortem opiate intoxication. Forensic Sci Int 2001; 120: 127-31.

8 - Carvalho LML, Linhares AX, Trigo JR. Determination of drug levels and the effect of diazepam on the growth of necrophagous flies of forensic importance in southeastern Brazil. Forensic Sci Int 2001; 120: 140-4.

9 - Kaneshrajah G, Turner B. Calliphora vicina larvae grow at different rates on different body tissues. Int $\mathrm{J}$ Legal Med 2004; 118: 242-4.
10 - Marchiori $\mathrm{CH}$ et al. Artrópodos associados com carcaça de suíno em Itumbiara, Sul de Goiás. Arq Inst Biol 2000; 67: 167-70.

11 - Andrade HTA, Varela-Freire AA, Batista MJA, Medeiros JF. Calliphoridae (Diptera) coletados em cadáveres humanos no Rio Grande do Norte. Neotrop Entomol 2005; 34 (5): 855-6.

12 - Carvalho LML, Thyssen PJ, Goff ML, Linhares AX. Observations on the succession patterns of necrophagous insects on a pig carcass in a urban area of Southeastern Brazil. Aggrawal's Internet J Forensic Med Toxicol 2004; 5 (1): 33-9.

Recebido para publicação em 27/08/2007

Aprovado para publicação em 13/05/2008 